British Journal of Psychiatry (1995), 166(suppl. 27), 19-22

\title{
The Social Costs of Anxiety Disorders
}

\author{
ANDREW C. LEON, LAURA PORTERA and MYRNA M. WEISSMAN
}

\begin{abstract}
Background. The social costs of anxiety disorders, which afflict a substantial proportion of the general population in the United States, are considered.

Method. Data from the National Institute of Mental Health (NIMH) Epidemiological Catchment Area Program were analysed.

Results. Over $6 \%$ of men and $13 \%$ of women in the sample of 18571 had suffered from a DSM-II! anxiety disorder in the past six months. Nearly $30 \%$ of those with panic disorder had used the general medical system for emotional, alcohol or drug-related problems in the six months prior to the interview. Those with anxiety disorders were also more likely to seek help from emergency rooms and from the specialised mental health system. Men with panic disorder, phobias or obsessive-compulsive disorder in the previous six months are more likely to be chronically unemployed and to receive disability or welfare.

Discussion. Once correctly diagnosed there are safe and effective psychopharmacologic and behavioural treatments for the anxiety disorders. Nevertheless the burden of anxiety disorders extends beyond the direct costs of treatment to the indirect costs of impaired social functioning.
\end{abstract}

It is estimated that nearly $15 \%$ of the general population in the US has suffered from at least one DSM-III anxiety disorder at some point in their lives (Regier et al, 1988). The lifetime rate of panic disorder is about 1.5\% (Eaton et al, 1991); for obsessive-compulsive disorder the lifetime rate is $2.5 \%$ (Karno \& Golding, 1991); the rates of phobias were most prevalent at about $14.3 \%$ (Eaton et al, 1991). Women consistently have about twice the rates of each anxiety disorder. Put in the context of the US population, these data show that over 30 million Americans have suffered from an anxiety disorder at some point.

The costs of anxiety disorders extend beyond those incurred from service utilisation to the indirect costs of impairment. Several researchers have examined the social morbidity that is associated with panic disorder (Markowitz et al, 1989; Weissman et al, 1989; Johnson et al, 1990; Klerman et al, 1991).

The objective of this report is to evaluate the social morbidity that is associated with each of the anxiety disorders. We examine financial dependence, help seeking, and drug and alcohol comorbidity among each of the diagnostic groups.

\section{Method}

The data come from the National Institute of Mental Health (NIMH) Epidemiological Catchment Area (ECA) Program, a survey of mental disorders in the United States (Regier et al, 1984; Robins et al, 1984;
Robins \& Regier, 1991). The ECA sample consisted of 18571 non-institutionalised adults from five US sites: New Haven, Connecticut; Baltimore, Maryland; Durham, North Carolina; St Louis, Missouri; Los Angeles, California. The data used in the analyses come from Wave I of that study.

The NIMH Diagnostic Interview Schedule (DIS) was used in the ECA. It is a structured diagnostic interview designed to be used by trained lay interviewers (Robins et al, 1981). Algorithms which employed the DSM-III criteria were used to determine the presence of diagnoses (American Psychiatric Association, 1980). The anxiety disorders that are included in the analyses are panic disorder, obsessive-compulsive disorder (OCD) and phobias (social, simple and agoraphobia pooled). In addition panic disorder, $O C D$ and phobias are pooled to create "any anxiety disorder". Other groups that were compared in the analyses include: those who reported panic attacks, but did not meet criteria for panic disorder; and those who had no Axis 1 disorder. In an attempt to disentangle the effects of comorbid major depressive disorder (MDD) on social morbidity, those with panic disorder were further classified as "panic disorder with MDD" or "panic disorder without MDD". Neither generalised anxiety disorder $(\mathrm{GAD})$ or post-traumatic stress disorder (PTSD) were included because those diagnoses were not part of Wave I of the five site ECA program. Comorbid drug and alcohol abuse or dependence were examined pooling abuse and dependence. 
The NIMH DIS also elicits information regarding occupational functioning, financial assistance, and help-seeking for emotional, drug or alcohol problems. Financial assistance that is examined includes receipt of disability, welfare or unemployment payments in the past six months. These forms of financial assistance are examined separately and combined to comprise "any financial assistance". The help-seeking behaviours that are examined below include use of the following service providers during the six months prior to the interview: general medical system, specialised mental health system, human services, and emergency room. All sources of help-seeking were combined to comprise "any help-seeking" in the past six months.

The weighted six month prevalence of each diagnostic group is reported. Six month prevalence was used to conform with the time frame that was available for service utilisation. The social costs are presented as rates of social morbidity among the groups of subjects who are classified according to the presence of each diagnosis in the past six months. All analyses (except prevalence) were conducted on unweighted data and were stratified by gender. Analyses of financial assistance and occupational functioning are limited to those from 18 to 65 years of age.

\section{Results}

The demographics of the sample are described in Table 1 . Over $6 \%$ of men and $13 \%$ of women had suffered from a DSM-III anxiety disorder in the six months prior to the DIS interview. More specifically, the six month prevalence of panic disorder was $0.5 \%$ for men and $1.0 \%$ for women; for $O C D$ the rates were $1.3 \%$ for men and $1.7 \%$ for women; the rates of phobias were $5.7 \%$ among men and $11.9 \%$ for women. Among those with panic disorder about $20 \%$ of the men and $30 \%$ of the women had comorbid MDD. In addition there was a substantial group (about $0.6 \%$ of men and $1.1 \%$ of women) who had panic attacks in the past six months, yet did not meet DSM-III criteria for panic disorder.

\section{Financial assistance}

Financial dependence is elevated among individuals with anxiety disorders (Table 2). About $20 \%$ of men in the sample without Axis I disorders were not currently employed, but about $36 \%$ of men with phobias, $45 \%$ with OCD, $60 \%$ with panic disorder
Table 1

Demographics of the ECA sample

Percentage of sample

\begin{tabular}{lc}
\hline $\begin{array}{l}\text { Gender } \\
\text { women }\end{array}$ & 59.0 \\
men & 41.0 \\
Race & \\
white & 65.5 \\
African-American & 23.5 \\
other & 11.0 \\
Marital status & \\
married & 46.8 \\
widowed & 17.7 \\
separated/divorced & 15.0 \\
Never married & 20.5 \\
Age (years) & \\
$18-24$ & 12.2 \\
$25-34$ & 21.9 \\
$35-44$ & 13.3 \\
$45-64$ & 22.0 \\
$65+$ & 30.5 \\
Mean (s.d.) & $48.89(20.21)$ \\
\hline
\end{tabular}

1. $n=18571$ non-institutionalised US adults.

and about $30 \%$ with subclinical panic attacks did not have jobs. For women there was less striking elevation in rates of unemployment associated with anxiety disorders.

There is also a greater chance of chronic unemployment (not employed for at least five years) among those with anxiety disorders (Table 2). Each anxiety disorder was associated with an increased rate of chronic unemployment for men, with panic disorder and OCD having the greatest elevation.

Men with panic disorder are about six times as likely to receive disability payments as those with no Axis I diagnosis; the rates of disability are somewhat lower for OCD and phobias (Table 3). Receipt of

Table 2

Employment status of the 18-64-year-olds in the sample (rate per 100)

\begin{tabular}{lrrrrr}
\hline & $\begin{array}{c}\text { Not currently } \\
\text { employed }\end{array}$ & $\begin{array}{c}\text { Not employed } \\
\text { in the past } \\
5 \text { years }\end{array}$ \\
\cline { 2 - 3 } \cline { 5 - 6 } Diagnosis (past six months) & Men & Women & & Men & Women \\
\hline Panic disorder & 60.00 & 68.57 & & 25.00 & 28.57 \\
$\quad$ panic disorder without MDD & 64.71 & 69.64 & & 29.41 & 28.57 \\
panic and major depression & 33.33 & 64.29 & & 0.00 & 28.57 \\
panic attacks (subclinical) & 29.73 & 55.67 & & 15.09 & 28.20 \\
Obsessive-compulsive & 44.78 & 65.25 & & 17.91 & 28.81 \\
Phobia & 35.69 & 54.05 & & 12.72 & 28.02 \\
No Axis I diagnosis & 21.05 & 45.92 & & 4.63 & 23.72 \\
\hline
\end{tabular}


Table 3

Current financial assistance (rate per 100 ) received by $18-64$-year-olds in the sample

\begin{tabular}{|c|c|c|c|c|c|c|c|c|}
\hline \multirow[t]{2}{*}{ Diagnosis (past six months) } & \multicolumn{2}{|c|}{ Disability payments } & \multicolumn{2}{|c|}{ Welfare } & \multicolumn{2}{|c|}{$\begin{array}{l}\text { Unemployment } \\
\text { compensation }\end{array}$} & \multicolumn{2}{|c|}{ Any assistance } \\
\hline & Men & Women & Men & Women & Men & Women & Men & Women \\
\hline \multirow{4}{*}{$\begin{array}{l}\text { Panic disorder } \\
\text { panic disorder without MDD } \\
\text { panic and major depression } \\
\text { panic attacks (subclinical) }\end{array}$} & 33.33 & 14.58 & 6.67 & 30.93 & 0.00 & 2.06 & 36.67 & 41.67 \\
\hline & 31.82 & 17.57 & 9.09 & 34.67 & 0.00 & 1.33 & 36.36 & 45.95 \\
\hline & 37.50 & 4.55 & 0.00 & 18.18 & 0.00 & 4.55 & 37.50 & 27.27 \\
\hline & 13.89 & 10.10 & 5.41 & 19.00 & 5.56 & 3.03 & 22.22 & 31.31 \\
\hline Obsessive-compulsive & 22.50 & 12.93 & 2.50 & 13.61 & 2.50 & 3.40 & 25.00 & 29.25 \\
\hline Phobia & 19.38 & 7.63 & 2.18 & 16.53 & 4.67 & 2.69 & 24.69 & 24.71 \\
\hline No Axis I diagnosis & 5.43 & 4.24 & 1.23 & 9.59 & 3.01 & 2.19 & 9.21 & 15.13 \\
\hline
\end{tabular}

welfare payments is also elevated among those with anxiety disorders. In the US this includes Aid for Dependent Children, thus the rates are higher among women. The elevation is greatest in women with panic disorder.

Taken as a whole, those with anxiety disorders received considerably more financial assistance than those with no mental disorder; gender differences disappear when the forms of financial assistance are combined.

\section{Help seeking}

The rates of seeking specialised mental health services (such as out-patient visits to a mental health specialist) are magnified for both men and women with anxiety disorders (Table 4). About one-third of those with panic disorder and nearly one-fifth of those with panic attacks or OCD seek help from a mental health specialist. This is considerably higher than about $2 \%$ of those with no Axis I diagnosis.

Those with anxiety disorders are also more likely to seek help in emergency rooms and from primary care practitioners (Table 4). For comparison, less than $4 \%$ of individuals without an Axis I diagnosis sought help from the general medical system for emotional or drug or alcohol-related problems in the prior six months. The rates were much higher for those with anxiety disorders, especially panic disorder (over $25 \%$ ). This might result from the physiological symptoms of a panic attack such as palpitations and shortness of breath - which mimic cardiac problems.

Taken as a whole, the help-seeking for emotional or drug or alcohol-related problems among anxiety disorder patients is very high. Over half of the patients with panic disorder seek help. Nearly $30 \%$ of those with other anxiety disorders, yet less than $10 \%$ of those with no diagnosis seek help for emotional problems.

\section{Substance abuse}

There were higher rates of alcohol and drug abuse and dependence among those suffering from anxiety disorders (Table 5). Women's rates of substance abuse and dependence were lower than men's. Nevertheless, women with anxiety disorders had higher rates of substance abuse than those with no Axis I diagnosis.

\section{Discussion}

The burden of anxiety disorders extends beyond the direct costs of treatment to the indirect costs

Table 4

Help seeking for emotional, drug or alcohol problems (rate per 100 ) by individuals in the sample in the past six months

\begin{tabular}{|c|c|c|c|c|c|c|c|c|c|c|}
\hline \multirow[t]{2}{*}{ Diagnosis (past six months) } & \multicolumn{2}{|c|}{$\begin{array}{c}\text { General medical } \\
\text { system }\end{array}$} & \multicolumn{2}{|c|}{$\begin{array}{l}\text { Specialised mental } \\
\text { health system }\end{array}$} & \multicolumn{2}{|c|}{ Human services } & \multicolumn{2}{|c|}{ Emergency room } & \multicolumn{2}{|c|}{ Any help seeking } \\
\hline & Men & Women & Men & Women & Men & Women & Men & Women & Men & Women \\
\hline Panic disorder & 33.33 & 25.93 & 36.67 & 31.48 & $\begin{array}{l}13.33 \\
13.64\end{array}$ & $\begin{array}{l}11.11 \\
12.20\end{array}$ & $\begin{array}{l}3.33 \\
4.55\end{array}$ & $\begin{array}{l}3.70 \\
4.88\end{array}$ & $\begin{array}{l}63.33 \\
68.18\end{array}$ & $\begin{array}{l}56.48 \\
56.10\end{array}$ \\
\hline panic disorder without MDD & 40.91 & 25.61 & $\begin{array}{l}31,82 \\
50.00\end{array}$ & & $\begin{array}{l}13.64 \\
12.50\end{array}$ & $\begin{array}{r}12.20 \\
8.00\end{array}$ & $\begin{array}{l}4.55 \\
0.00\end{array}$ & $\begin{array}{l}4.08 \\
0.00\end{array}$ & $\begin{array}{l}00.10 \\
50.00\end{array}$ & $\begin{array}{l}56.10 \\
60.00\end{array}$ \\
\hline panic and major depression & 12.50 & 28.00 & $\begin{array}{l}50.00 \\
16.28\end{array}$ & $\begin{array}{l}36.00 \\
20.17\end{array}$ & $\begin{array}{r}12.50 \\
2.33\end{array}$ & 6.72 & 0.00 & 1.68 & 32.56 & 32.77 \\
\hline panic attacks (subclinical) & 13.95 & 13.45 & 16.28 & & 4.04 & 4.35 & 0.00 & 0.00 & 24.24 & 27.72 \\
\hline Obsessive-compulsive & 7.07 & 11.96 & $\begin{array}{r}17.17 \\
8.33\end{array}$ & $\begin{array}{r}16.30 \\
7.53\end{array}$ & 3.92 & 4.71 & 1.23 & 0.78 & 17.40 & 20.00 \\
\hline Phobia & $\begin{array}{l}8.33 \\
1.93\end{array}$ & $\begin{array}{r}10.67 \\
3.80\end{array}$ & $\begin{array}{l}8.33 \\
1.70\end{array}$ & $\begin{array}{l}7.53 \\
2.13\end{array}$ & 1.05 & 1.94 & 0.07 & 0.18 & 4.35 & 7.19 \\
\hline
\end{tabular}


